\title{
El médico ante las enfermedades mortales: el caso del cáncer
}

\author{
Hernán Cortés-Funes \\ Servicio de Oncología Médica. Hospital Universitario 12 de Octubre, Madrid
}

\section{INTRODUCCIÓN}

La profesión médica tiene en general unas connotaciones muy especiales al actuar sobre individuos semejantes en los que la acción profesional tiene enorme ascendencia. Si bien existen enormes variables en éstos hechos en relación a las diferentes especialidades médicas, siempre, los valores de la actuación médica son una herramienta muy delicada de manejar.

Cuando nos centramos en pacientes portadores de procesos graves que puedan llevar a un desenlace fatal el problema se complica mucho más. Dentro de estos procesos el Cáncer reúne a una serie de enfermedades muy variables cuya evolución puede desembocar en el fallecimiento del paciente aunque otras veces esa posible evolución es sólo un temor del paciente y su entorno al lograr el paciente, por intervención de tratamientos efectivos, superar su enfermedad de manera parcial o definitiva.

Es por esto que considero de fundamental importancia el analizar éstas distintas posibles evoluciones con objeto de establecer de manera precisa el verdadero papel del médico ante un cáncer de evolución mortal.

Lo mas importante al realizar éste análisis es tratar de fijar una serie de conceptos actuales en relación a las enfermedades tumorales, para no llamarlas cáncer, y a partir de ellos llegar a definir verdaderamente la situación de paciente con un proceso de muerte inminente y ver realmente que papel juega el médico especialista en dicho momento.

En primer lugar debemos aclarar el significado de la propia palabra "Cáncer" ya que la evolución de los conocimientos de los mismos proceso hasta los enormes logros terapéuticos alcanzado hoy en día, nos llevan a la necesidad de tamizar dicha palabra en lo que he denominado "Cambios Conceptuales sobre el Cáncer”, que siempre introducimos en la mayoría de nuestros seminarios y actividades docentes.

Cuando hablamos de Cáncer en nuestro medio tenemos en mente una situación, en general, muy mala y, con frecuencia, muy distante a de la realidad.

En general la palabra CANCER, tiene muchas connotaciones, generalmente distintas de la realidad. Se la emplea como sinónimo de algo terrible, cercano a lo peor que le pueda suceder a alguien y es por ello que la gente tiene temor a padecerlo. Incluso la palabra tiene connotaciones dramáticas en su empleo habitual. Periodísticamente se hace alusión al "Cáncer" cuando se quiere significar algo trágico o tremendo....ETA es el "Cáncer de la sociedad...., o Ben Laden es el "Cáncer" de la humanidad. Incluso cuando se quieren referir a la enfermedad procuran no utilizarla y emplean terminologías que ensombrecen mas su significado tales como: "portador de una enfermedad incurable o "murió de una larga y penosa enfermedad"....

Es triste que eso suceda ya que mantiene el "tabú" sobre un conjunto de enfermedades que si bien es verdad que en muchas ocasiones son muy graves y acordes a dichos conceptos, existen otras ocasiones, generalmente mucho mas frecuentes, que ello no es así.

Cáncer comprende a un conjunto de procesos de todo tipo, de acuerdo a numerosos factores, tal como sucede con todas las enfermedades. Desde situaciones iniciales perfectamente solucionables con tratamientos simples, generalmente erradicativos hasta situaciones extremadamente graves.

El concepto actual del cáncer es muy distinto al clásico regionalista de los cirujanos de antes. Las 
enfermedades malignas (los cánceres) son enfermedades que muchas veces se encuentran extendidas en el momento del diagnóstico. En ocasiones la enfermedad se puede erradicar, cuando se diagnostica en situación localizada, alcanzando remisiones duraderas mediante tratamientos locorregionales con cirugía y radioterapia.

En el pasado, basados en que la única arma terapéutica existente frente a los tumores malignos era la cirugía, las enfermedades malignas se clasificaban de acuerdo a su extensión anatómica en el momento del diagnóstico en operables, cuando se encontraban en situación localizada, o inoperables, cuando se encontraban extendidas a distancia. La operabilidad de los procesos era sinónimo de curabilidad, y por el contrario cuando el tumor era inoperable por su extensión o una vez operado recaía el paciente era considerado como incurable. Estos conceptos, que desgraciadamente prevalecen en el momento actual, sobre todo a nivel de los pacientes y sus familiares, y que eran correctos hace mucho tiempo, hay que desvirtuarlos por múltiples razones.

En primer lugar porque se conoce mucho más y de mejor manera el desarrollo de los distintos tumores y por otro lado se cuenta con muchos más tratamientos tanto locales como generales, que aportan importantes cambios en todos los estadios de las distintas enfermedades. Por todo ello en el momento actual existe un cambio muy significativo en el "Objetivo Terapéutico" que se quiere obtener y que resulta sumo interés el aclararlo.

Desgraciadamente muchas veces la enfermedad, a pesar de la erradicación inicial, vuelve a salir. Este hecho se explica en parte con los conocimientos actuales sobre las bases biológicas del cáncer, que identifica alteraciones genéticas presentes, no sólo en las células del tumor erradicadas sino en otras células del organismo huésped que si bien tienen aspectos histológicos de normales, con técnicas habituales, pueden evolucionar hacia la malignidad y provocar una recaída o un nuevo tumor primario.

Un hecho conocido desde hace mucho tiempo es que las células malignas originadas en el tumor primario, migran tempranamente a distancia $\mathrm{y}$ generalmente no se las pueden detectar con las técnicas diagnósticas habituales. Ello significa que a pesar de estar un tumor limitado a su región o área de origen, determinado por la metodología clásica de estudio de extensión, a veces la enfermedad se puede encontrar ya extendida en otros sitios del organismo. Estas células denominadas células dor- midas, son las causantes (o no) de las recaídas de un proceso aparentemente localizado. Este hecho apoya cada vez más la combinación de tratamientos locales con tratamientos generales a distancia, como es la administración de quimioterapia antes de la cirugía o inmediatamente después de la misma.

\section{PLANTEAMIENTO ANTE LA ENFERMEDAD}

Cuando se diagnostica un tumor maligno se plantean distintas situaciones que el paciente debe conocer y el médico saber transmitir. La enfermedad puede ser erradicable de manera definitiva, es decir curable, o no, es decir incurable. Esta última situación no indica que no pueda ser tratable, lo que implica que se dispone de procedimientos terapéuticos que mejoren su situación, reduciendo la sintomatología que produce e incrementando la supervivencia del paciente. Ahí es donde la información que el médico debe aportar al paciente y sus familiares resulta fundamental, dado que muchas veces no se llega a comprender bien ésta situación. La posibilidad de tratamiento efectivo es un hecho real en muchas enfermedades incurables que habitualmente la gente padece, tal como sucede con la diabetes, hipertensión, cardiopatías, etc. pero que al no ser un cáncer la gente asume sin mayores temores. Esas enfermedades, al igual que muchas otras, son tan incurables como el cáncer que aún sin curación pero con tratamiento efectivo, ya que son enfermedades crónicas, objetivo actual de los nuevos tratamientos oncológicos. En la Tabla 1 se detallan estos cambios sobre los conceptos tradicional y actual del cáncer, y en la Tabla 2 se puede ver un listado de las enfermedades crónicas incurables pero tiene un tratamiento efectivo, entre las que se encuentra el cáncer en recaída.

En la Figura 1, se esquematiza la evolución de un tumor y las distintas intenciones terapéuticas posibles. En general, el tumor se diagnostica cuando el paciente presenta síntomas que aparecen cuando alcanza cierto volumen y afecta estructuras sensibles. Existe previamente un período pre-sintomático, que en ciertos tumores sólidos, y basados en la extrapolación de datos sobre tiempos de duplicación celular, puede llegar a ser de años (6-8 años en cáncer de mama), durante los cuáles el paciente se encontraba en situación normal y sin síntomas, pero con su tumor. Si la enfermedad no se ha extendido, hecho que desconocemos a ciencia cierta, la aplicación de un tratamiento quirúrgico puede llegar a eliminarla de mane- 
Tabla 1: Cambios Conceptuales en Cáncer

\section{Concepto tradicional}

\section{Concepto Actual}

- Curable

- Incurable

- Operable

- No Operable

Escasa efectividad de

los Tratamientos

Doloroso con muchos

sintomas (sufrimiento)

Mortal en poco tiempo,

solo admite tratamientos

paliativos

Enfermedad Mortal
Tipos de Cáncef Curable

- Tratable

Tratamientos

- Curativos ( multidiciplinarios )

- No Curativos

Alta efectividad de los

Tratamientos

Prolongación supervivencia

Erradicación de síntomas

Convivir con la enfermedad

Enfermedad Crónica

Tabla 2: Enfermedades Crónicas Incurables (Con Tratamiento Efectivo)

- Hipertensión

- Diabetes

- Insuficiencia Cardíaca

- Miocarditis (infarto)

- Arterioesclerosis

- Insuficiencia Renal

- Hepatitis

- Tóxica

- Infecciosa (viral)
- Artritis, Artrosis

- Depresión

- Migrañas / Jaquecas

- Insuficiencia Respiratoria

- Enfisema

- Bronquitis Crónicas

- Asma

- Cáncer Recaído

- Mama, Colorectal

- Ovario, Linfomas.... ra definitiva aunque, como ya se ha dicho, la enfermedad al cabo de un tiempo puede recaer y entonces el planteamiento terapéutico deberá ser diferente.

Existe otra situación diferente es aquella en la que en el momento del diagnostico la enfermedad se encuentre en situación avanzada y no susceptible de erradica y el paciente no haya tenido síntomas hasta ese momento. Es entonces donde debemos considerar alternativas terapéuticas que se limiten sólo a revertir la situación sintomática del tumor a la previa, hecho fácilmente alcanzable con los tratamientos actuales. Esa es una línea de trabajo actual, con una base empírica pero muy realista y que se está estudiando con los nuevos agentes con mecanismo de acción sobre inhibición del crecimiento celular anteriormente mencionados, que podrían 


\section{Figura 1: Intenciones terapéuticas en Oncología}

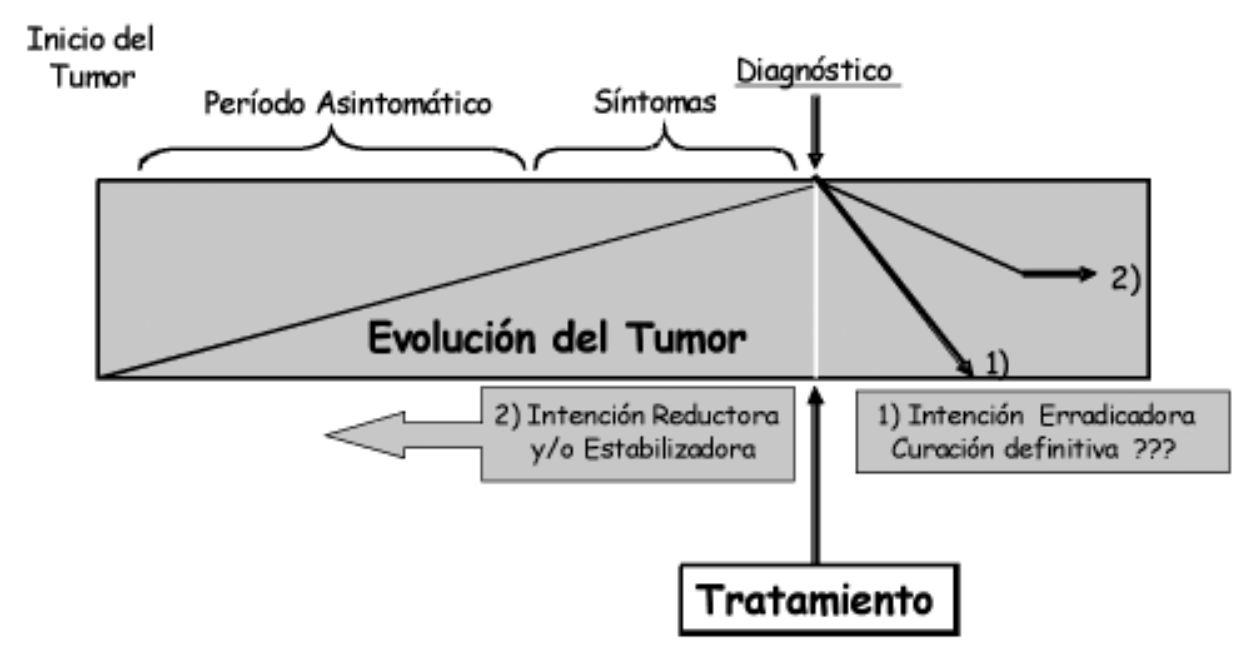

extender situaciones de respuestas parciales o estabilidad durante períodos prolongados de tiempo. En los nuevos estudios en marcha se le está dando cada vez más importancia a parámetros tales como tiempos hasta progresión, supervivencia global, además de las duración de las respuestas y beneficio clínico.

\section{AVANCES TERAPÉUTICOS}

Con los tratamientos actuales, se dice que podemos curar cerca de la mitad de los procesos a lo que habrá que añadir un $35 \%$ de casos en que si bien el tumor no se puede eliminar si se pueden aplicar tratamientos efectivos que alivien los síntomas y prolonguen la vida de los pacientes. Dicho de otra forma, en el momento actual mas de un $80 \%$ de los pacientes con cáncer se pueden beneficiar de un tratamiento efectivo, hecho que no sucede en muchas enfermedades a las que en general no se le tiene tanto temor como al cáncer, generalmente por desconocimiento de éstos datos.

Que esto sea así se debe a la evolución de todos las distintas armas terapéuticas que en la actualidad se dispone, que junto con la incorporación de tratamientos nuevos, han logrado incrementar el índice de curación y sobre todo el tiempo de supervivencia de los pacientes, especialmente en cierto tipo de tumores.

La Radioterapia, segunda arma curativa después de la cirugía, actualmente se administra con Aceleradores Lineales que logran destruir las célu- las tumorales residuales después de la cirugía o tumores situados en zonas no accesible por la misma. Con las nuevas técnicas de campos conformados y de Intensidad modulada se logra administrar dosis de irradiación tan efectivas que han logrado reemplazar la propia cirugía, tal como sucede con el cáncer de mama, de laringe, vejiga, próstata, etc.

También contamos con fármacos nuevos más activos que administrados en combinación provocan importantes respuestas con incremento significativo de la vida de los pacientes. Esta quimioterapia, se puede administrar en pacientes con recidivas o avanzados o de manera complementaria a la cirugía y radioterapia cuando el paciente tiene riesgo de recaer. También se administra como primer tratamiento (quimioterapia primaria o neoadyuvante) en tumores difíciles de resecar por su tamaño. Entre ellos podemos mencionar a los taxanos (paclitaxel $y$ docetaxel), los nuevos platinos (oxaliplatino), los nuevos agentes denominados intercalantes (irinotecan, topotecan, antraciclinas liposomales), y los nuevos agentes hormonales como los inhibidores de aromatasa (letrozol, anastrazol, examestano) y los nuevos antiestrógenos (fulvestran).

Sin embargo, lo más importante entre los avances terapéuticos ha sido el desarrollo e incorporación de los nuevos agentes antitumorales que actúan por mecanismos diferentes de las hormonas y la quimioterapia, denominados agentes que actúan sobre Nuevas Dianas (Targeted Agents). Estos comprenden una serie de moléculas pequeñas de diseño o 
Figura 2: Evolución de la Supervivencia en relación a los Tratamientos en el Carcioma Colorectal Avanzado

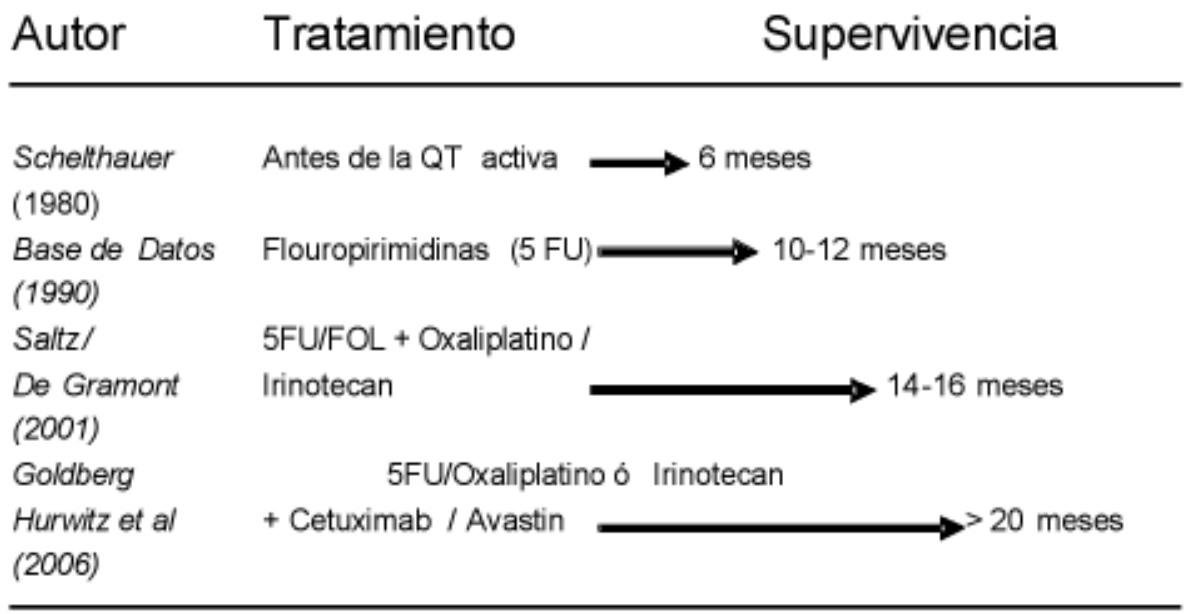

Weyerhandt, J. A. et al. N Engl J Med 2005; 352:476 -487

moléculas grandes como los Anticuerpos Monoclonales, que intervienen inhibiendo o bloqueando las señales de crecimiento de las células tumorales. La gran ventaja de éstos nuevos agentes, además de su alta efectividad como agentes únicos o potenciadores de la quimioterapia, es su baja toxicidad que permite administraciones prolongadas de fácil manejo. Entre las moléculas pequeñas cabe destacar el Imatinib para leucemias resistentes y tumo- res no quimiosensibles como el GIST, el Erlotinib para el cáncer de pulmón, el Sorafenib y Sunatinib para el cáncer de riñón, etc. Entre los Anticuerpos Monoclonales disponemos de Trastuzumab para el cáncer de mama, el Cetuximab para el cáncer de colon y tumores de cabeza y cuello, y el Bevaci$z u m a b$ para el cáncer colorectal, cáncer de mama y cáncer de pulmón.

En la Figura 2, como mero ejemplo de muchas

\section{Figura 3: Árbol de decisiones para el final de la vida}

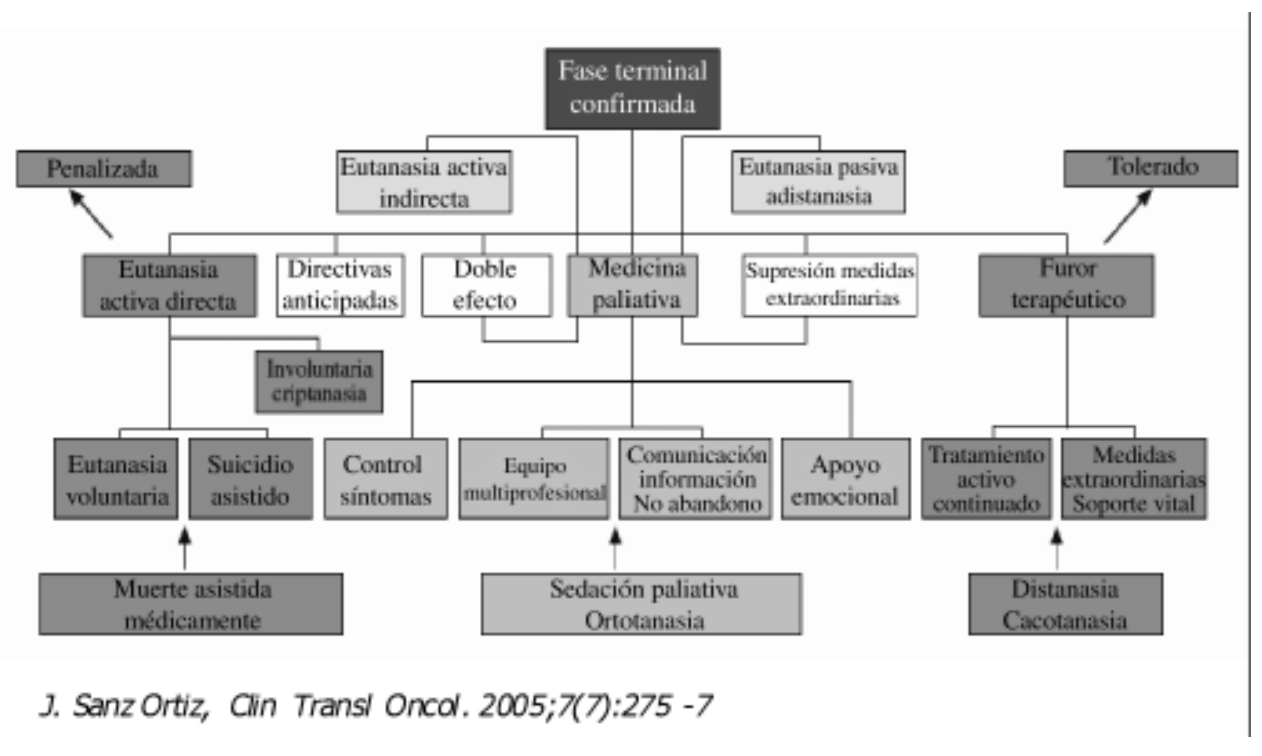




\begin{tabular}{|c|c|}
\hline Eutanasia activa & Sedación \\
\hline Intención & Intención \\
\hline Hacer daño (matar) & Beneficiar (adquinir confort) \\
\hline Relación médico-paciente: & Relación médico-paciente \\
\hline Traiciona la confianza en el médico & Refuerza confianza en el médico \\
\hline Método & Método \\
\hline Inducir parada respiratoria & Inducir inconsciencia o sueño \\
\hline Fármacos & Fámacos \\
\hline Barbitúricos y miorrelajantes & Opioides y Benzodiacepinas \\
\hline Fundamento & Fundamento \\
\hline Matar por piedad & Principio doble efecto \\
\hline Resultado & Resultado \\
\hline Muerte debida a fármacos & Muerte debida a enfermedad \\
\hline Legislación & Legislación \\
\hline $\begin{array}{l}\text { No permitida } 95 \% \text { países fuera de "la } \\
\text { lex artis" }\end{array}$ & $\begin{array}{l}\text { Permitida } 100 \% \text { incluida en } \\
\text { "la lex artis" }\end{array}$ \\
\hline
\end{tabular}

situaciones similares, podemos ver la evolución de la supervivencia de los pacientes con Cáncer de Colon y Recto avanzado a lo largo de los años con la incorporación de los distintos tratamientos nuevos. En menos de 10 años hemos multiplicado casi por cuatro la supervivencia de éstos pacientes.

\section{ACTITUD DEL MÉDICO ANTE EL PACIENTE TERMINAL}

A pesar de los buenos datos expresados en el punto anterior, muchas veces el paciente se hace refractario a todas las medidas terapéuticas activas frente a su enfermedad y su evolución siguiente es sin duda su fallecimiento a un plazo relativamente corto. Por ello, resulta sumamente importante el manejo efectivo de ésta situación, denominada "terminal" con objeto de poder dar al paciente la mejor calidad de vida, a través de la aplicación de tratamientos sintomáticos que deben ser tan efectivos como los tratamientos ante su enfermedad.

$\mathrm{Al}$ igual que ha sucedido en el momento del diagnostico, resulta importante el dar una información adecuada al paciente y su familia en el momento de una situación de enfermedad terminal "confirmada" de acuerdo a la denominaciónacordada por los expertos en éstos temas.

En la Figura 3 se detallan las distintas situaciones existentes en torno a un paciente de éste tipo, que como puede verse es sumamente compleja y por ello requiere una atención muy especial. Lo fundamental es la identificación adecuada de ésta situación terminal y posteriormente la aplicación correcta, en cada caso, del tratamiento más conveniente. Como complemento de éstos conceptos creo muy importante el establecer, de acuerdo a los expertos en éstos temas tres conceptos muy importantes:

Sedación: administración deliberada de fármacos sedantes en las dosis y combinaciones requeridas, para reducir la consciencia de un paciente con enfermedad avanzada y terminal, cuya muerte está próxima, tanto como sea preciso para aliviar adecuadamente uno o más síntomas refractarios y con su consentimiento explícito, implícito o delegado ( $J$. Porta y cols).

Síntoma refractario: Síntoma que no puede ser adecuadamente controlado a pesar de los intensos esfuerzos para encontrar un tratamiento tolerable en un plazo de tiempo razonable sin que comprometa la conciencia del paciente (Cherny y Portenoy).

Eutanasia: Conducta (acción u omisión) intencionalmente dirigida a terminar con la vida de una persona enferma, con una enfermedad grave e irreversible, por razones compasivas, en un contexto médico y con el consentimiento del enfermo (SEC$P A L, 2002)$.

Finalmente en la Tabla 3 se puede ver claramente la diferencia entre la eutanasia activa y la sedación, conceptos muchas veces confundidos hasta por los propios médicos. 
Considero fundamental que los médicos que se enfrenten a éstas situaciones conozcan y puedan saber diferenciar éstos conceptos, aunque su aplicación deberá estar a cargo de equipos especializados para evitar situaciones inadecuadas como ha sucedido recientemente en nuestro entorno.

\section{CONCLUSIONES}

La asistencia del médico al paciente en el período final de su vida plantean en la actualidad cada vez mas problemas que no solo están relacionados con la vertiente médica sino también con el mundo jurídico y con el complejo mundo de los valores éticos.

El médico tiene la obligación no solo de saber curar (Ciencia), sino de saber hacer (Arte), y todo ello emplearlo, en todo momento, en el transcurso de la enfermedad.

Ante la Muerte inminente del paciente, ambas cualidades deberán ser desarrolladas y aplicadas al máximo de sus posibilidades de acuerdo a la preparación y valores éticos del médico.

\section{BIBLIOGRAFÍA}

1. Fidler IJ. Cancer: Principles \& Practice of Oncology. 5th ed. $1997 ; 141$

2. De Vita VT et al, Principle \& Practice of Oncology; 7th Edition, Lippincott Williams, 2005.

3. Hanahand D, Weinberg R. The Hallmarks of Cancer. Cell, 2000:100, 57-70

4. Slamon DJ, Leyland-Jones B, Shak S, et al. Use of Chemotherapy plus a Monoclonal Antibody against HER2 for Matastatic Breast Cancer that Ovrexpresses HER2: N Engl J Med 2001, 344:783-792

5. Meyerhardt, J. A. et al. N Engl J Med 2005;352:476-487

6. Hurwitz, H. et al. N Engl J Med 2004;350:2335-2342

7. Drucker BJ, Talpaz M, Debra J et al. Eficcacy and Safety of a Specific Inhibitor of the BCR-ABL Tyrosine Kinase in Chronic Myeloid Leukemia. N Engl J Med, 2001; 344:1031.

8. Gonzalez Baron m y cols. Tratado Cuidados Paliativos

9. J. Sanz Ortiz y cols, Clin Transl Oncol. 2005;7(7):275-7

10. Porta J y cols. Aspectos éticos de la sedación en C.P.Med Pal 2002;9:41-5

11. V. Valentin y cols Clin Transl Oncol. 2005;7(7):285-94.

12. Sociedad Española de Cuidados Paliativos, Definición de Eutanasia, 2002. 